\title{
Giant Condyloma Acuminata with Maggots in Perianal Area of HIV Infected Male Running Head: A Case Report of Giant Condyloma Acuminata
}

\author{
Parajuli $S^{1}$, Shrestha $A^{2}$, Paudel $U^{3}$
}

\section{ABSTRACT}

We report a case of 28-year-old HIV-positive male with giant condylomaacuminata in anogenital region. This homosexual patient presented with a large foul smelling growth along with maggots in a perianal region refractory to treatment at presentation. The patient was successfully managed with excision and there was no recurrence of lesion at last follow-up at 2-months. The case highlights the rare presentation and management of difficult-to-treat case of giant condylomaacuminata with maggots of anogenital region in HIV-positive patients.

\section{Key words: Buschke-Lowenstein tumour, Condylomataacuminata, Papilloma virus infections}

1. Sudip Parajuli

2. Amrita Shrestha

3. Dr. Upama Paudel

Address for correspondence:

UpamaPaudel

Associate Professor

Department of Dermatology and Venereology

Maharajgunj Medical Campus, Institute of Medicine

Email : upama_ups@yahoo.com

\section{INTRODUCTION}

Giant Condylomaacuminata (Buschke-Lowenstein Tumor) is a rare sexually transmitted diseases which present as large exophytic cauliflower like lesion of the anogenital region with histological characteristics of condyloma acuminata ${ }^{1,2}$. About 630 million new cases of Human Papilloma Virus (HPV) infection occur each year, out of which 30 million develop anogenital warts. It is seen that men who have sex with men (MSM) have highest prevalence of anal $\operatorname{HPV}(57 \%)^{3}$. We report a case of giant condylomaacuminata of anogenital region in HIV infected patients.

\section{Case report}

A 28- year-old homosexual and HIV infected male patient on anti-retroviral treatment (4-months) presented to us with large exophytic genital wart arising from perianal area of 6 months duration (Figure 1).

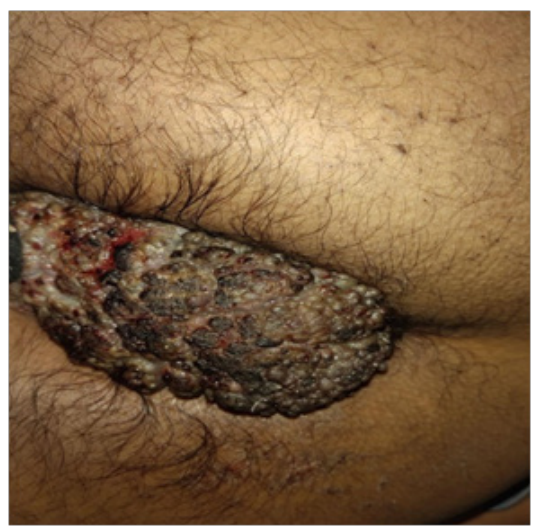

Figure 1
There was history of rapid growth of the lesion since 2 months. The large growth caused difficulty in gait and defecation. Patient developed severe itching, bleeding, pain and insect crawling sensation in the lesion for past 1 week prior to hospital visit. His lesion in perianal area was secondarily infected and was associated with foul smell and maggots (Figure 2).

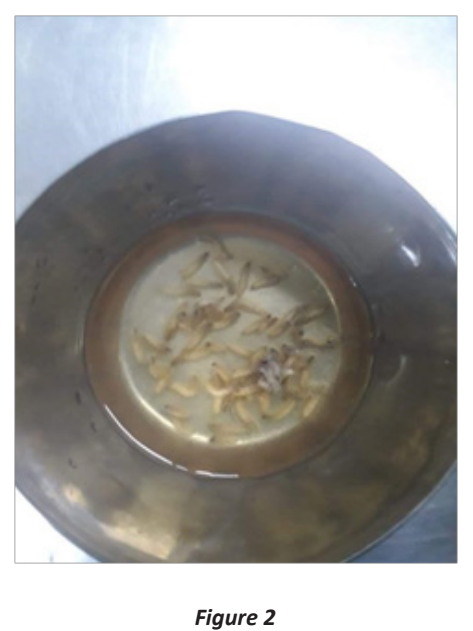

Cutaneous examination revealed $10 \times 7 \times 5 \mathrm{~cm}$ size hyperpigmented, reddish to brown colored, well-circumscribed, pedunculated fungating growth with multiple crusts and verrucous surface over perianal area. There was no lymphadenopathy. The lesion was foul smelling and on close inspection maggots were crawling from inner surface. His CD4 count was 624cells/ul and viral loadwas 53 copies/ml.

Histopathological examination revealed marked papillomatosis, acanthosis, hyperkeratosis, parakeratosis and crust formation. 
Focal koilocytic cells were seen. Dermis showed dense lymphoplasmocytic and neutrophilic infiltration as well as marked pigment incontinence. No granuloma, dysplasia and malignancy was seen (Figure 3).

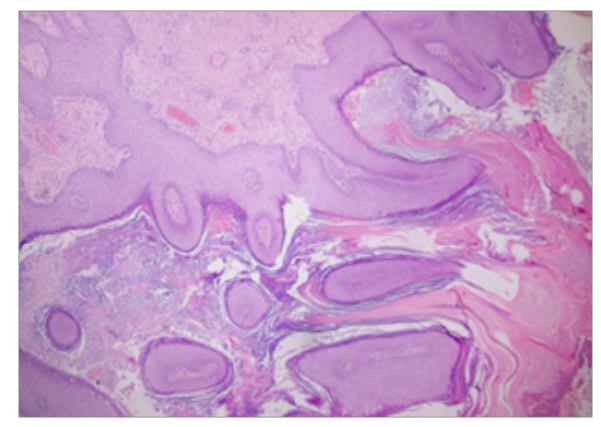

Figure 3

Patient was treated with multiple application of Podophyllinand single application of imiquimodbefore presenting to our center. To reduce the size of tumor, acitretin $25 \mathrm{mg}$ two times a day was given for 3 months. As there were multiple number of maggots in the mass, the maggots was extracted by turpentine oil application.Antibiotic coverage(Intravenous Ceftriaxone and metronidazole) was done for secondary infection. Local excision was done under spinal anesthesia. There was no recurrence of lesions at last follow up at 2 months(Figure 4).

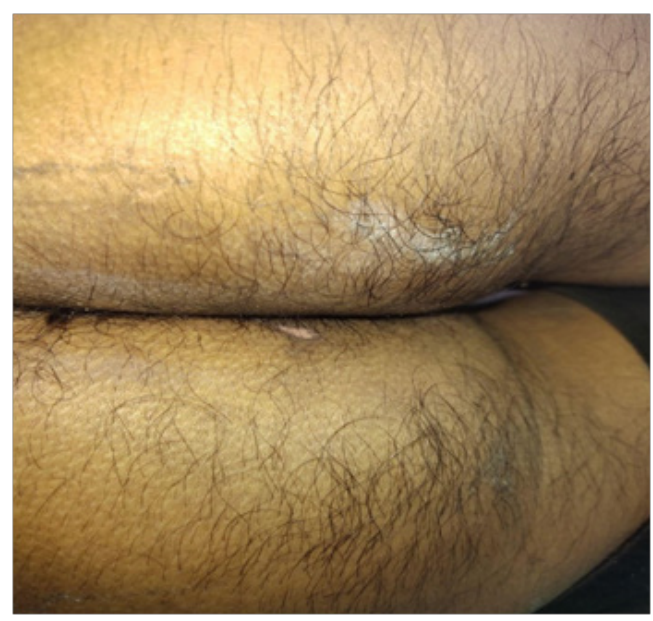

Figure 4

\section{DISCUSSION}

There is paucity of literatures on giant condylomaacuminata of anogenital region in HIV infected patients.Our patient was unusual in terms of rare presentation with development of giant tumour despite normal CD4 count. Moreover, the picture was complicated by development of maggots within the lesion.

HPV is an epidermotropic DNA virus which causes various benign and malignant lesions involving the anogenital region. Almost 120 types of HPV have been identified, of which 40 of them primarily infect the squamous epithelium of lower anogenital tract of men and women ${ }^{4}$.
Giant Condylomaacuminatum develops by overgrowth of condylomaacuminatum and has high risk for malignant transformation. Intra-anal warts in HIV-positive men who have sex with men can contain regions of high-grade anal intraepithelial neoplasia. They may additionally present as pelvic pain, perianal secretion, anorectal bleeding and anal sphincter incontinence.

Anogenital wart of HIV-infected patients differ from those of HIV-negative individuals with respect to their spread, occurrence on more unusual anatomical sites, tendency to recur and risk of malignant transformation. Around 18 and 56\% of anogenital warts of HIV-positive patients has high-grade dysplasia, which calls for early recognition and treatment of this condition. It is a slow growing, locally invasive and verrucous appearing tumor that does not spontaneously resolve. The progression from condylomaacuminatum probably occurs during the immune suppression, such as congenital or acquired immunodeficiency, alcoholism, diabetes or chemotherapy with immunosuppressive therapy.Contrary to earlier belief, sexually transmitted diseases of the anorectum, including HPV, are not limited to homosexual men, and it is important for both the primary care physician and the colorectal surgeon recognize recent trends in sexual behavior. With increase in prevalence of HIV and AIDS, an increase in Giant Condylomaacuminata and associated malignancy can be expected ${ }^{1}$.

Podophyllotoxin is not currently recommended for giant condyloma as its use may cause histological changes that resembles carcinoma and cause diagnostic difficulties ${ }^{5}$.

Early complete surgical resection is essential for optimal treatment of giant Condylomaacuminataandabdominoperineal resection should be done wherever necessary ${ }^{1}$.

Advantages of surgical approach is that it allows tissue biopsy for diagnosis, requires fewer physicin visits than medical treatment and has excellent clearance with lower recurrence rate $^{3}$.

Abdominoperineal resection should be done for any patient demonstrating external anal sphineter involvement ${ }^{1}$.

As relapse and even malignant transformation of condyloma have been reported, close follow-up is recommended, especially, for lesions positive for high-risk HPV types ${ }^{4}$. TheHPV vaccine could lead to a potential reduction in the incidenceof genital warts as well as cervical, anal, vulvar, cancers and its precursor lesions ${ }^{4}$.

Quadrivalent HPV vaccine is effective for preventing anogenital warts in young males in Male having sex with $\mathrm{Men}^{3}$.

\section{CONCLUSION}

Giant condylomaacuminata with maggots in anogenital region is a rare case presentation in homosexual HIV positive male patient. The diagnosis is usually made on clinical ground and histopathological examination is necessary to rule out malignant transformation. Surgical treatment offers a greater possibility of cure compared to other forms of treatment. 


\section{REFERENCES}

1. Trombetta LJ, Place RJ. Giant condyloma acuminatum of the anorectum: trends in epidemiology and management: report of a case and review of the literature. Dis Colon Rectum 2001; 44(12): 1878-86.

2. Tas S, Arik MK, Ozkul F, Cikman O, Akjun Y. Perianal giant condyloma ccuminatum-Buschke-Löwenstein Tumor: a Case Report. Case Rep Surg. 2012; 2012:507374. doi: 10.1155/ 2012/507374. Epub 2012 Nov 20.

3. Assi R, Reddy V, Einarsdottir H, Longo WE. Anorectal human papillomavirus: current concepts. Yale J Biol Med. 2014 Dec 12;87(4):537-47. PMID: 25506286; PMCID: PMC4257038.

4. Bhageerathy PS, Cecilia M, Sebastian A, et al. Human papilloma virus-16 causing giant condyloma acuminata. J Surg Case Rep. 2014;2014(1):rjt126. Published 2014 Jan 27. doi:10.1093/jscr/ rjt126

5. Chowdri, N.A., Gagloo, M.A., Parray, F.Q. et al. Indian J Surg (2007) 69: 203. https://doi.org/10.1007/s12262-007-0023-3 